\title{
PENGEMBANGAN MARKETING PRODUCT PROFILE PADA CV NOOR MANDIRI ROTAN
}

\author{
Putri Kurnia Handayani \\ Dosen Fakultas Teknik, Program Studi Sistem Informasi \\ Universitas Muria Kudus \\ Email: putri.kurnia@umk.ac.id \\ Noor Latifah \\ Dosen Fakultas Teknik, Program Studi Sistem Informasi \\ Universitas Muria Kudus \\ Email: noor.latifah@umk.ac.id \\ Syafiul Muzid \\ Dosen Fakultas Teknik, Program Studi Sistem Informasi \\ Universitas Muria Kudus \\ Email: syafiul.muzid@umk.ac.id
}

\begin{abstract}
ABSTRAK
Promosi merupakan suatu aktivitas dan materi pemasaran yang dalam aplikasinya menggunakan teknik, dibawah pengendalian penjual/produsen, yang dapat mengkomunikasikan informasi persuasif yang menarik tentang produk yang ditawarkan oleh penjual/produsen, baik secara langsung maupun melalui pihak yang dapat mempengaruhi pembelian. CV Noor Mandiri merupakan salah satu produsen furniture dengan bahan baku rotan dan pelepah pisang di Jepara. Area pemasaran yang luas mencakup seluruh wilayah Indonesia dan ekspor ke Malaysia, menyebabkan CV Noor Mandiri memerlukan sebuah strategi pemasaran yang baik untuk dapat mengembangkan jangkauan pemasaran yang telah ada saat ini. Salah satu alternatif yang dapat diterapkan untuk melakukan strategi pemasaran ini adalah melalui digital marketing product profile. Digital marketing product profile yang dapat diterapkan CV Noor Mandiri adalah dengan membuat promosi produk furniture melalui video sehingga konsumen dapat melihat produk secara nyata dari semua titik pandang. Metode penelitian menggunakan penelitian deskriptif yaitu metode penelitian yang bertujuan menggambarkan secara sistematis dan akurat mengenai data yang ada melalui tahapan wawancara, observasi dan studi literatur untuk kemudian dianalisis dengan teori yang ada. Tahapan perancangan meliputi pra-produksi, produksi dan pasca produksi. Hasil penelitian berupa video product profile CV Noor Mandiri yang dapat digunakan sebagai media promosi.
\end{abstract}

Kata kunci: digital marketing, video product profile.

\begin{abstract}
Promotion is an activity and marketing material in its application using techniques, under the control of the seller / producer, who can communicate interesting persuasive information about the products offered by the seller / producer, either directly or through a party that may affect the purchase. $C V$ Noor Mandiri is one of the producers of furniture with raw materials of rattan and banana tree in Jepara. The vast marketing area encompasses all parts of Indonesia and exports to Malaysia, causing $C V$ Noor Mandiri to require a good marketing strategy to be able to expand the existing marketing reach. One alternative that can be applied to perform this marketing strategy is through digital marketing product profile. Digital marketing product profile that can be applied CV Noor Mandiri is to make promotion of furniture products through video so that consumers can see the product in real from all points of view. The research method used descriptive research that is research method that aims to describe systematically and accurately about the existing data through the stages of interviews, observation and literature studies to then be analyzed with existing theories. Stages of design include preproduction, production and post production. The results of the video product profile CV Noor Mandiri that can be used as a media campaign.
\end{abstract}

Keywords: digital marketing, video product profile. 


\section{PENDAHULUAN}

Perkembangan teknologi sangat berdampak pada peradaban manusia, yang bergantung pada teknologi. Teknologi informasi merupakan suatu alat/tool dalam sebuah sistem informasi yang dibangun pada suatu bisnis. Persaingan bisnis yang semakin ketat di era globalisasi menuntut perusahaan untuk menyusun/meninjau ulang strategi bisnis yang dilakukan. Esensi dari persaingan terletak pada bagaimana sebuah perusahaan dapat mengimplementasikan proses penciptaan produk atau jasanya secara lebih murah, baik, cepat dan unik disbandingkan dengan pesaing bisnisnya.

CV Noor Mandiri merupakan salah satu perusahaan yang bergerak di bidang produksi furniture di Teluk Wetan Jepara dengan bahan baku rotan dan pelepah pisang. Area pemasaran hasil produksi meliputi seluruh wilayah di Indonesia dan sudah mulai ekspor ke Malaysia. Jangkauan pemasaran yang semakin luas membuat perusahaan berupaya menerapkan strategi bisnis baru dengan tujuan mempertahankan dan memperluas area pemasaran.

Marketing product profile merupakan salah satu teknik untuk menentukan strategi pemasaran bisnis yang terdiri dari 4P, yaitu product, price, place dan promotion. Produk merupakan hasil baik barang maupun jasa yang memenuhi target pasar yang mempunyai nilai teknologi dan packaging. Promosi adalah kegiatan memperkenalkan produk kepada calon konsumen. Proses ini erat kaitannya dengan proses branding. Promosi produk dapat dilakukan melalui banyak cara salah satunya adalah melalui video product profile.

Teknik multimedia yang dipakai dalam pembuatan video product profile bukan hanya menyediakan banyak teks melainkan juga menghidupkan teks dengan menyertakan gambar, audio (suara dan musik), animasi dan video ( (Suyanto, 2005).

Penyampaian informasi mengenai jenis pembelajaran, cara pembelajaran merupakan salah satu cara menginformasikan suatu lembaga pendidikan agar dapat diketahui masyarakat. Aplikasi multimedia yang merupakan penggabungan dari beberapa komponen seperti teks, suara, gambar dan animasi akan membuat pengguna menjadi nyaman dalam menikmati informasi yang disajikan ( (Sadono, 2012).

Multimedia menjadi penting karena sebagai salah satu media yang dipakai dalam persaingan perusahaan. The Geek, Apple Authorised Reseller Yogyakarta merupakan salah satu perusahaan yang bergerak dibidang penjualan komputer yang dalam hal ini sangat memerlukan sarana informasi sebagai media promosi (Momintan \& Kharisma, 2013).

PT. Tarindo merupakan salah satu perusahaan yang memproduksi kran air yang ada di Indonesia. Peyampaian informasi tentang produk Tarindo masih memiliki kelemahan yaitu masih diinformasikan oleh bagian penjualan kepada konsumennya. Peran multimedia dirasakan perlu untuk memperluas pangsa pasar dari produk Tarindo salah satunya adalah pembuatan company product profile dengan menggunakan software Adobe Premiere (Hartanto, 2014).

Pembuatan company profile juga diterapkan di SMP N 4 Karanganyar sebagai media promosi ke masyarakat agar sekolah tersebut semakin dikenal di masyarakat. Melalui video company profile masyarakat lebih bisa menikmati informasi yang disampaikan perusahaan/instansi karena tidak hanya melalui media teks tetapi juga gambar, audio, video dan animasi ( (E.P, 2013).

Media Christopherus menggunakan video company profile untuk media pemasaran. Pemasaran yang dilakukan perusahaan selama ini melalui brosur dan leaflet yang dirasakan kurang mengena di masyarakat sebab berupa kertas yang kemungkinan masyarakat tidak akan membaca ( (Utomo, 2012).

\section{METODOLOGI PENELITIAN}

\subsection{Metode Penelitian}

Penelitian ini menggunakan metode penelitian deskriptif dimana metode penelitian ini bertujuan untuk menggambarkan secara sistematis dan akurat mengenai data-data yang ada dengan cara mengumpulkan dan mengklarifikasi data yang diperoleh untuk kemudian dianalisis dengan menggunakan teori yang dipelajari. Teknik pengumpulan data meliputi wawancara, observasi dan studi pustaka.

\subsection{Perancangan}

Sejalan dengan tujuan yang ingin dicapai yakni Pengembangan Digital Marketing Product Profile pada CV Noor Mandiri maka metode pengembangan ini melalui 3 tahapan, yaitu pra-produksi, produksi dan pasca produksi (Gambar 1). 
a. Pra-produksi

Tahap awal atau persiapan pembuatan digital marketing product profile meliputi pengumpulan materi outline dari perusahaan yang berisi shooting objective, durasi, target audience dan setting/tempat. Setelah materi terkumpul, diseleksi untuk kemudian dibuatkan naskah/script digital marketing product profile.

b. Produksi

Tahap pembuatan digital marketing product profile. Tim pengabdian dan tim pemasaran perusahaan melakukan pengambilan gambar, video sesuai dengan naskah yang telah dibuat sebelumnya. Pengambilan gambar dapat dilakukan secara acak, tidak harus urut sesuai naskah. Pada tahap ini semakin banyak video, gambar yang dihasilkan akan lebih baik.

c. Pasca produksi

Langkah terakhir dalam pembuatan digital marketing product profile adalah proses editing. Proses editing terdiri dari merangkai gambar secara kasar berdasarkan naskah/script. Selanjutnya memperhalus gambar melalui grafis dan terakhir pewarnaan atau colour grading. Preview pertama hasil digital marketing product profile ditampilkan pada tim pemasaran perusahaan, revisi dilakukan sesuai permintaan perusahaan. Pada minggu terakhir juga akan dilakukan pelaporan semua kegiatan yang telah dilakukan.

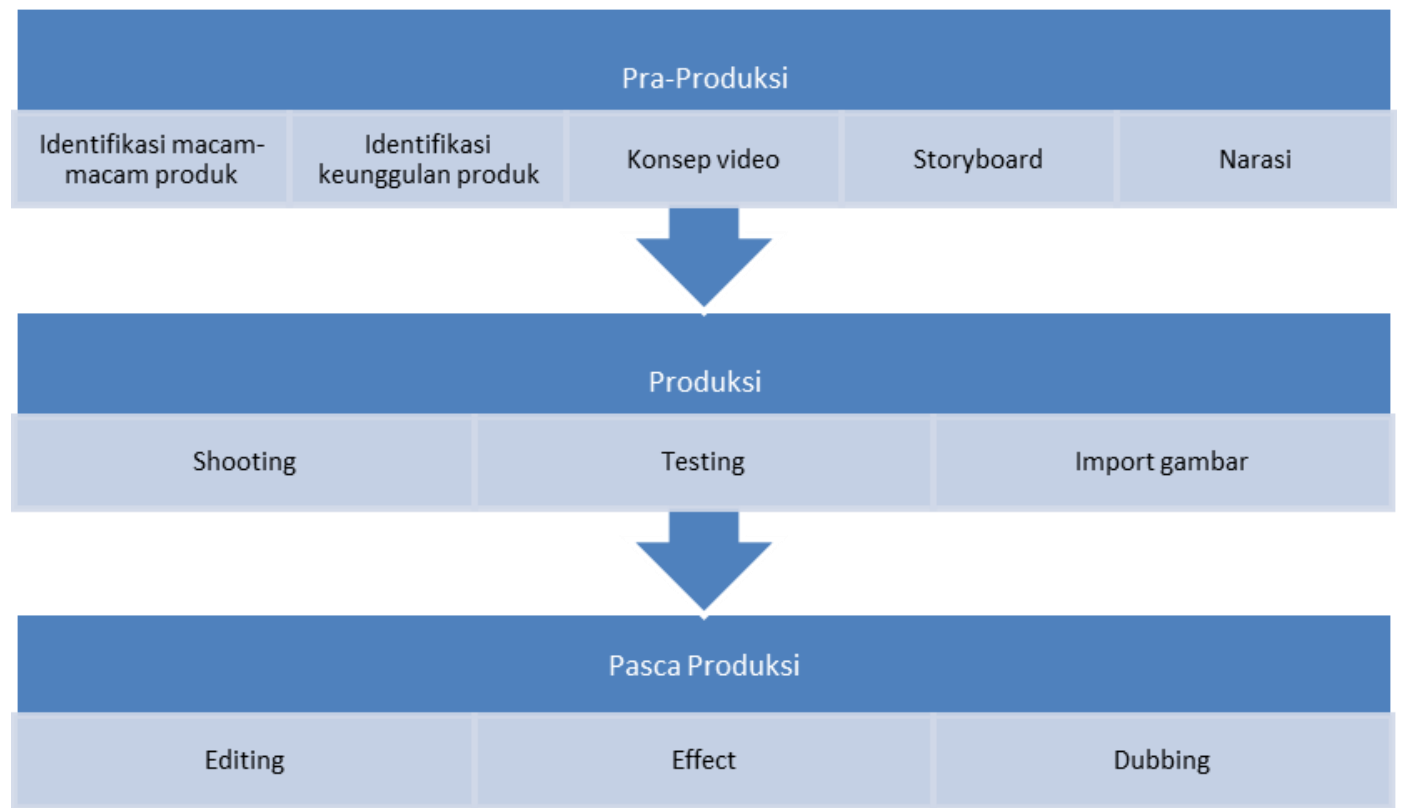

Gambar 1. Diagram Tahapan Pembuatan Video Product Profile

\section{HASIL PENGEMBANGAN}

Sesuai dengan tahapan pengembangan digital marketing yang direncanakan, maka hasil yang dicapai adalah sebagai berikut:

\subsection{Konsep Video Product Profile}

Video yang dibutuhkan dalam pemasaran produk CV Noor Mandiri terdiri dari informasi profil perusahaan, proses produksi dan macam-macam produk yang dihasilkan. Konsep video yang akan dibuat adalah:
a. Opening, nama perusahaan yaitu CV Noor Mandiri dan profil
b. Tampilan macam-macam produk diantaranya kursi
c. Pengambilan gambar bahan baku dari rotan
d. Tampilan proses produksi meliputi pemilihan bahan baku, pembuatan kerangka dan penganyaman.

\subsection{Shoting Script Pembuatan Kursi Rotan}

Setelah mempelajari teknik pengambilan gambar dan video, langkah selanjutnya adalah membuat naskah untuk pembuatan produk profile. Berikut salah satu contoh shoting script pembuatan kursi rotan (tabel 1). 
Tabel 1. Shoting script pembuatan kursi rotan

\begin{tabular}{|c|c|c|c|}
\hline No & Video/Adegan & Audio/Narasi & Durasi \\
\hline 1 & Opening & Back sound, Sound Effect & $20 "$ \\
\hline \multirow[t]{9}{*}{2} & Shot tempat pembuatan furniture: & Back sound & $30 "$ \\
\hline & 1. Shot jalanan (LS) & & \\
\hline & 2. Shot pengrajin per lokasi & & \\
\hline & $\begin{array}{l}\text { 3. Shot beraneka ragam rotan } \\
\text { (CU) }\end{array}$ & & \\
\hline & 4. Shot expresi pengrajin (CU) & & \\
\hline & $\begin{array}{l}\text { 5. Shot saat pengrajin memilah } \\
\text { rotan (MS) }\end{array}$ & & \\
\hline & $\begin{array}{l}\text { 6. Shot pengrajin yang memproses } \\
\text { rotan (MS) }\end{array}$ & & \\
\hline & 7. Shot brand showroom CV Noor & & \\
\hline & Mandiri Rotan (Zoom Out, LS) & & \\
\hline \multirow[t]{5}{*}{3} & Shot pengupasan & -Narasi- & $10 "$ \\
\hline & 1. Shot rotan kering (LS) & & \\
\hline & 2. Shot pengrajin mengupas & & \\
\hline & kulit rotan (MS) & & \\
\hline & 3. Shot expresinya (CU) & & \\
\hline \multirow[t]{3}{*}{4} & Shot saat penganyaman: & -Narasi- & $10 "$ \\
\hline & 1. Shot perajin menanyam (LS) & & \\
\hline & 2. Shot ekspresi (FS) & & \\
\hline \multirow[t]{3}{*}{5} & Shot mengecat: & -Narasi- & $10 "$ \\
\hline & $\begin{array}{l}\text { 1. Shot perajin mengecat rotan } \\
\text { (MS) }\end{array}$ & & \\
\hline & 2. Shot expresinya(CU) & & \\
\hline \multirow[t]{4}{*}{6} & Shot finishing: & -Narasi- & $20 "$ \\
\hline & $\begin{array}{l}\text { 1. Shot alat finishing <amplas, } \\
\text { kompor, dll> }(\mathrm{CU})\end{array}$ & & \\
\hline & 2. Shot proses amplas (MS) & & \\
\hline & 3. Shot expresinya & & \\
\hline 7 & Closing & & $20 "$ \\
\hline
\end{tabular}

\subsection{Pengambilan Gambar dengan Teknik Close Up}

Ada beberapa teknik pengambilan gambar dan video diantaranya close up (Gambar 2) dan long shot (Gambar 3). Berikut contoh hasil pengambilan gambar dengan teknik close up:

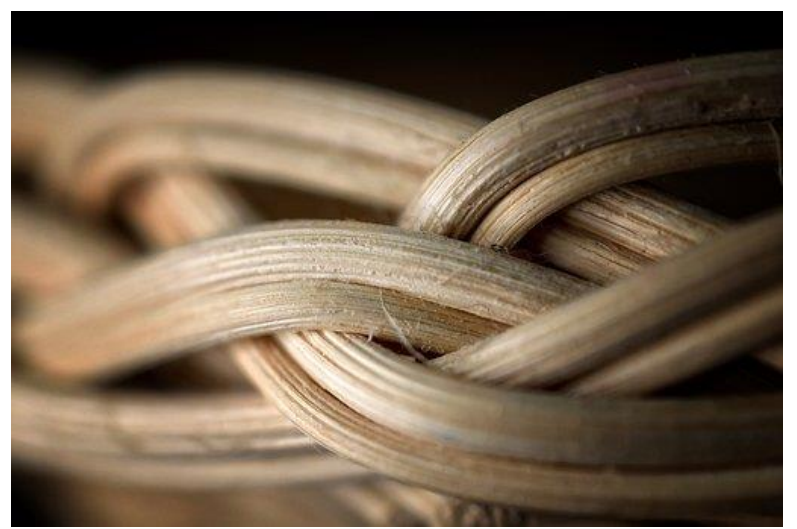

Gambar 2. Foto Rotan dengan Teknik Close Up 


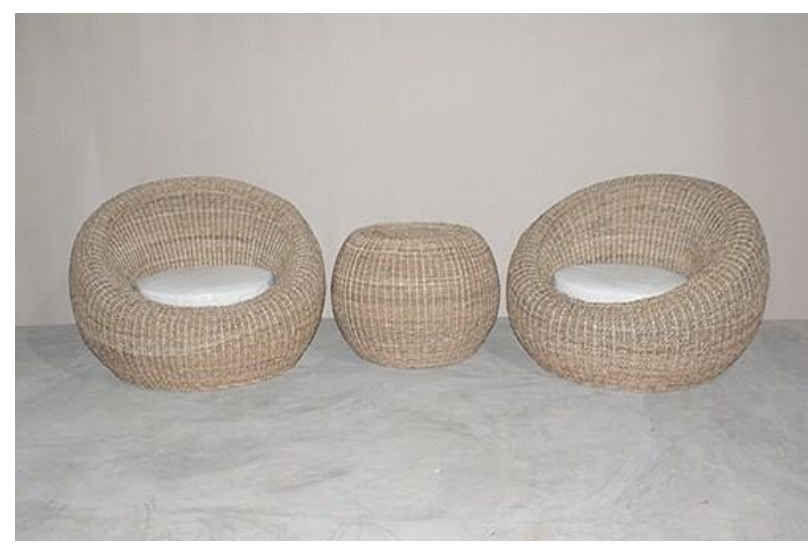

Gambar 3. Foto Produk dengan Teknik Long Shot

\subsection{Video Profile}

Proses editing dilakukan setelah kegiatan pengambilan gambar selesai. Proses editing terdiri dari merangkai gambar secara kasar berdasarkan naskah/script. Selanjutnya memperhalus gambar melalui grafis dan terakhir pewarnaan atau colour grading. Preview pertama hasil digital marketing product profile ditampilkan pada tim pemasaran perusahaan, revisi dilakukan sesuai permintaan perusahaan. Video opening setelah melalui proses editing (gambar 4), video pemilihan bahan rotan (gambar 5), video pembuatan kerangka kursi rotan (gambar 6) dan video proses menganyam rotan secara tradisional (gambar 7).

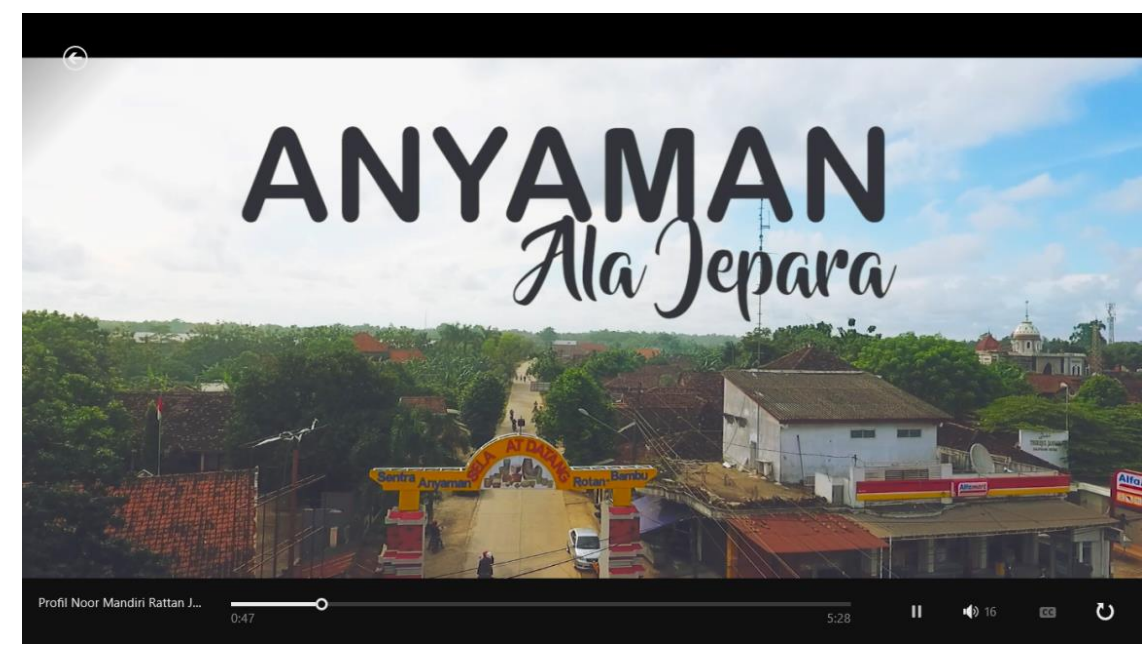

Gambar 4. Video Opening

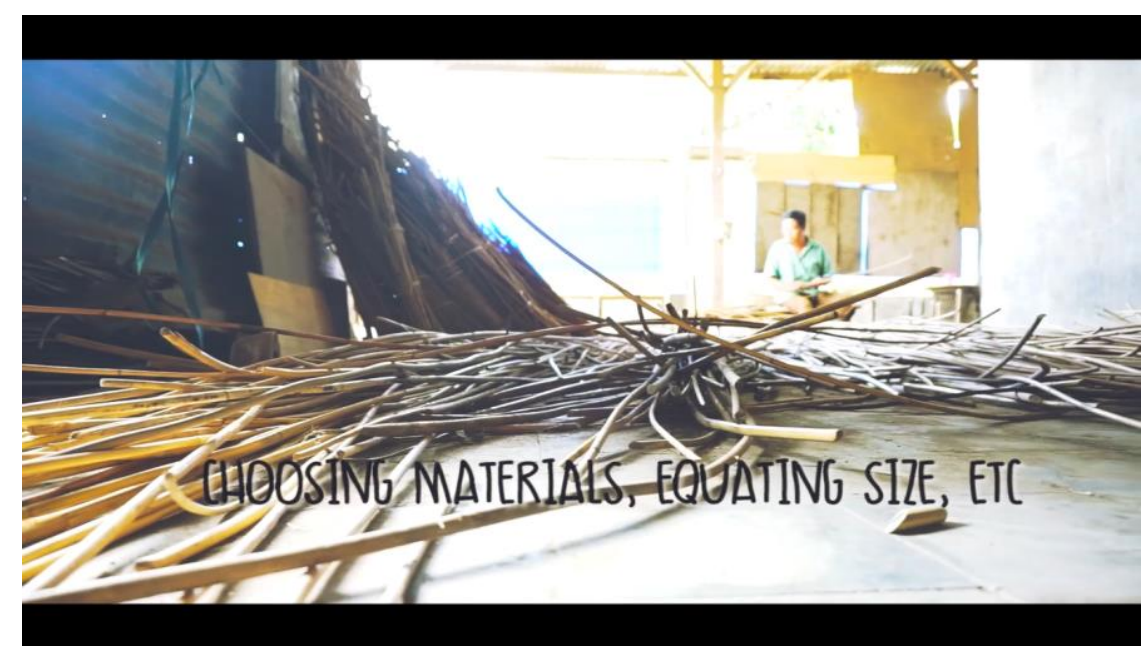

Gambar 5. Pemilihan Bahan Rotan 


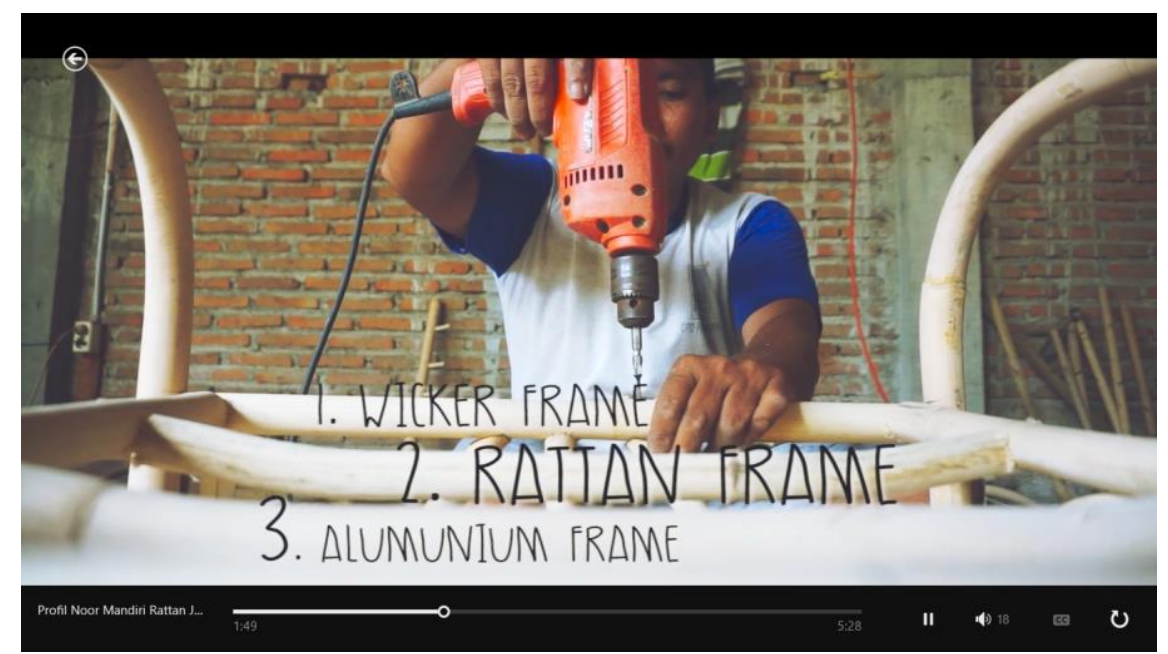

Gambar 6. Proses Pembuatan Kerangka Kursi Rotan

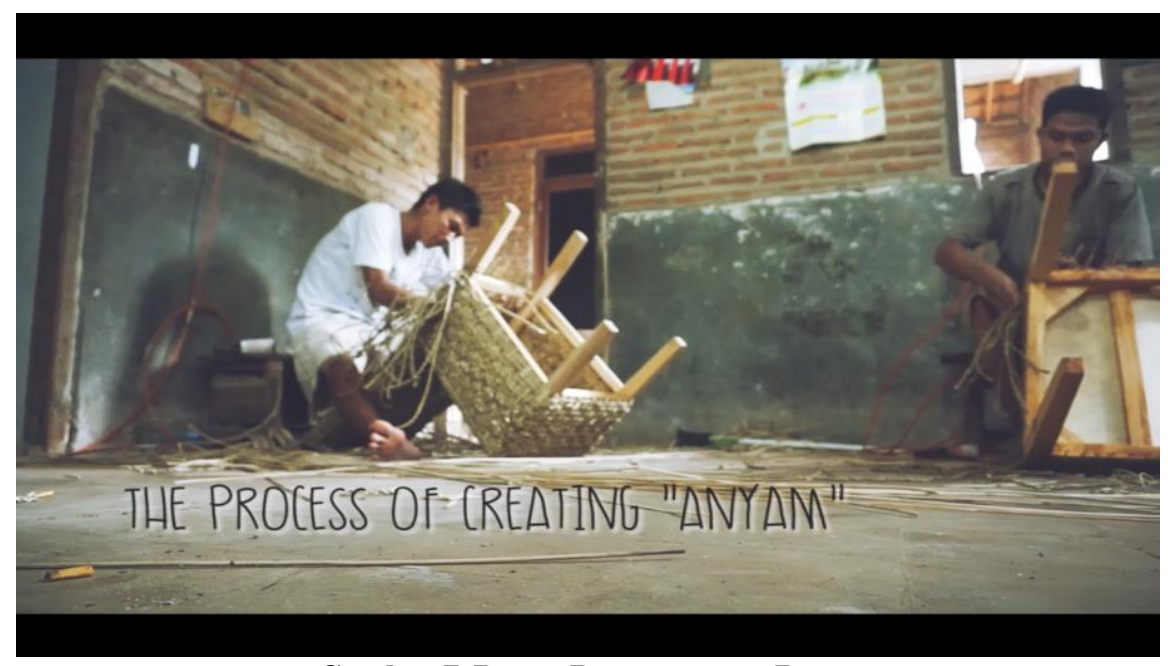

Gambar 7. Proses Penganyaman Rotan

\section{KESIMPULAN}

Pengembangan digital marketing berupa video product profile telah berhasil dibuat. Proses pembuatan video product profile melalui 3 tahap, yaitu pra-produksi, produksi dan pasca produksi. Hasil akhir dari kegiatan ini adalah video product profile yang dapat digunakan oleh CV Noor Mandiri untuk kegiatan promosi.

\section{DAFTAR PUSTAKA}

[1] E.P, S. W. (2013). Pembuatan Video Company Prifle Berbasis Multimedia pada Sekolah Menengah Pertama Negeri 4 Karanganyar. Seminar Riset Unggulan Nasional Informatika dan Komputer. Surakarta: FTI UNSA.

[2] Hartanto, R. D. (2014). Analisa dan Pembuatan Video Product Profile PT. Tarindo untuk Meningkatkan Citra Perusahaan Sebagai Produsen Kran Air.

[3] Momintan, M. A., \& Kharisma, R. S. (2013). Perancangan Company Profile The Geek Apple Authorized Reseller Yogyakarta Berbasis Multimedia Flash Sebagai Sarana Promosi dan Informasi. Dasi .

[4] Rudy. (2010). Perancangan E-Marketing Bagi Pemasaran Produk Kecantikan. Seminar Nasional Informatika 2010 (semnasIF 2010) UPN "Veteran" Yogyakarta, (pp. E-174 - E-182). Yogyakarta.

[5] Sadono, D. S. (2012). Pembuatan Company Profile Interaktif DIII-Teknik Informatika Universitas Sebelas Maret Surakarta.

[6] Suyanto, M. (2005). Multimedia Alat untuk Meningkatkan Keunggulan Bersaing. Yogyakarta: Andi.

[7] Utomo, M. K. (2012). Pembuatan Company Profile pada Media Christopherus Semarang. 